\title{
Mechanical and Metallurgical Examinations of Stir Cast Aluminum Matrix Composites: A Review Study
}

\author{
Narinder kaushik $^{\# 1}$, Sandeep Singhaal ${ }^{* 2}$ \\ ${ }^{\text {\#} R e s e a r c h ~ S c h o l a r ~ D e p a r t m e n t ~ o f ~ M e c h a n i c a l ~ E n g i n e e r i n g ~}$ \\ NIT Kurukshetra, Kurukshetra-136118, Haryana, India \\ 1'narinderkaushik83@gmail.com \\ *Associate Professor Department of Mechanical Engineering \\ NIT Kurukshetra, Kurukshetra-136118, Haryana, India \\ ${ }^{2}$ Sandeep_singhaal_reck@rediffmail.com
}

\begin{abstract}
The drift of research work from monolithic aluminum alloy to composite materials like Metal Matrix Composites (MMC's) is due to the world-wide proviso for economical, high working performance and superior quality materials. Metal matrix composites especially aluminum matrix composites (AMC's) due to their excellent strength with respect to their weight, superior wear resistance, economical and high corrosion resistance are extensively produced and utilized in several applications like, architectural components, structural applications, aerospace, automobile industry, ship building and many sports items and electrical and electronic components. The reinforcements like SiC, $\mathrm{B}_{4} \mathrm{C}, \mathrm{Al}_{2} \mathrm{O}_{3}, \mathrm{TiB}_{2}, \mathrm{Red}$ mud, Graphite, Fly ash, and Coconut ash etc. can be easily incorporated as reinforcement agents in the molten melt by employing the economical and widely used stir casting technique, which improves strength, stiffness, fatigue, hardness, wear and creep properties of the AMCs. This paper gives an overview of mechanical, microstructural and wear performances of aluminum centered metal matrix composites produced by stir casting process reinforced with single and multiple types of reinforcements. The problems like reinforcement-metal matrix bonding, distribution of particles, wettability of reinforcing particles and agglomeration phenomenon are discussed in this paper. The effect of various reinforcement particles on aluminum matrix composites on mechanical properties like uts, ys, stiffness, hardness, fatigue, \% E, wear and on resulting microstructure is discussed. The Modified and dual step stir casting technique for the fabrication of AMCs is also discussed in this paper.
\end{abstract}

Keywords: Aluminum matrix composite (AMC), stir casting, reinforcement, mechanical properties, wear behavior

\section{INTRODUCTION}

Metal based matrix composites reinforced with ceramic agents have a wide range of applications in aerospace, automobile, structural components and defense sector. Monolithic aluminum alloys have limitations in achieving good combinations of mechanical properties like strength, toughness, stiffness, wear resistance and density. Metal matrix composites are produced to overcome these shortcomings and to encounter the worldwide requirement for light weight materials with higher specific strength, corrosion resistant, high stiffness and excellent wear resistant properties [1-2]. The properties of aluminum alloy like low density, light weight, easy processing technique and fine engineering characterstics favored it as matrix material in MMC's [3]. The aluminum matrix series like AA2xxx, AA5xxx, AA6xxx, and AA7xxx have numerous applications in aerospace, defense instrument, architectural and structural components, automobile, sports good, and ship building [1-4].

For the fabrication of metallic matrix composites several type of manufacturing methods are employed. The choice of appropriate manufacturing method highly alters the resulting composite microstructure, dispersion of ceramic agents, interfacial bonding between the matrix phase and reinforcement particle and mechanical performances [5]. The manufacturing method to be employed is greatly based upon the type of reinforcement and metallic material. The major disadvantage behind producing aluminum matrix composites (AMC's) generally rests on the very expansive cost of production and reinforcement material. The economical and easy technique for production of composite materials is very important for elaborating their applications and properties. Stir casting and modified stir casting (two step stir casting) techniques are attracting researchers due to economical and easy method of processing. Several processing techniques which have shown to be comparatively expensive and complex in operation like in-situ casting, powder metallurgy and squeeze casting are also available. This paper gives a delineate review of production of aluminum centered metal matrix composite (AMC's) by using stir casting techniques and improvement in their microstructural, mechanical and wear performance. 


\section{MATERIALS AND METHODS}

\section{A. Stir casting}

In the conventional and cost effective stir casting technique, normally reinforcement in the form of particles like $\mathrm{SiC}, \mathrm{Al}_{2} \mathrm{O}_{3}, \mathrm{TiC}, \mathrm{MgO}, \mathrm{B}_{4} \mathrm{C}$ etc. are incorporated into the aluminum matrix melt by creating forced vortex stirring action. The homogeneous dispersion of the reinforcing agents is a key challenge in the processing of composite materials in order to achieve a defect free microstructure. The reinforcement phase depending on size in the composite may be either in the particle form or fiber form. Particulate reinforced composites comparatively has cheap material cost and suitability of manufacturing method over fiber reinforced composite and that is why they are more preferable over fiber reinforced composites.

In early stage reported literature stir casting was first introduced in 1968 by S.Ray. Ray fused $\mathrm{Al}_{2} \mathrm{O}_{3}$ particles into aluminum melt by stirring molten al-alloy carrying the reinforcement particles [6]. A key constituent of this process is the mechanical vortex stirring of viscous metallic melt in the furnace. The charged al-alloy melt containing reinforcing agents can then be processed by utilizing any method like mold casting, sand casting or die casting etc. Stir casting method is appropriate to produce composites upto $30 \mathrm{vol} . \%$ fraction of particles reinforcement [7-8]. Many aluminum matrix composites with various matrix compositions, such as AA6061 [9], AA6063 [10], Al-Si-Fe alloys [11], AA1070 and AA6063 [12], AA356 [13], AA6061 [14] have been produced successfully using stir casting technique. A homogeneous distribution and strong bonding of secondary particles in the composite matrix is critical for executing a high strength. The uneven distribution and weak bonding can lead to premature failures in reinforcement rich and reinforcement free zones. In reinforcement free areas under an applied load, slip of dislocations and initiations of microcracks can occur easily, eventually resulting in failure of the material. Agglomeration or clustering of reinforcing particles causing a weak bond formation, which can bring to reduce the mechanical properties. The homogeneous dispersion of the ceramic agents in the resulting casting is based on the intensity of mixing, wettability between the molten melt and reinforcement particles solidification time and the relative density. Stirring temperature, design of the stirrer, stirring speed, stirrer position into the melt and properties of the reinforcement agents decides the dispersion of ceramic particles in the molten alloy matrix [15-16].

Two step mixing is the recent and interesting growth in stir casting technique [17]. In this technique, firstly the matrix alloy is heated above its liquidus temperature to ensure complete melting. The temperature of the molten metal is then lowers down in between the liquidus and solidus points such that the molten slurry remains in a semi-solid state. The preheated reinforcement particles are mixed into the semi-solid slurry by manual stirring at this stage. The slurry containing the reinforcement particles is again heated just above its liquids temperature and at this stage stirring is done with the help of a suitably designed mechanical stirrer. The obtained microstructure of the composite made by two step stir casting process is more uniform than that produced with traditional stirring mechanism. The main advantage of dual step stir casting process is mainly ascribed to its capability to crack the layer of gas around the surface of the reinforcement particles. The wettability between the molten melt and reinforcing particles is reduced due to the absorption of thin layer of gas around the surface of reinforcement particles. The stirring of the reinforcing agents in the viscous state helps more effectively to crack the layer of gas because of the abrasive action of the high viscosity of the molten melt. The addition of suitable stirring mechanism like mechanical stirring, centrifugal stirring, and electromagnetic stirring enhanced the use of stir casting technique for metal composite processing [18].

\section{B. Wettability}

Wettability between the matrix alloy and reinforcing particles is one of the most crucial factor in liquid metal handling and processing. In stir casting process when the wettability is low the mechanical stirring thrust is indispensible to overcome the surface energy barrier to make a powerful bond between the reinforcement phases and the liquid metal. The surface energy of reinforcement and matrix material and the surface condition of the ceramic particles are the two important factors on which the wettability between the matrix material and reinforcement phase largely depends [19]. Wettability between metal matrix and ceramic phase can be enhanced by decreasing the surface tension of the molten metal, increasing the surface energy of the solid and decreasing matrix-particle interface energy through adding additives to melt, coating of particles, subjecting the melt to ultrasonic irradiation and heating and cleaning of the particles [20-21]. The addition of Mg metal powder greatly enhanced the dispersion of Silicon carbide particles in the composite just before the introduction of the reinforcing agents or in advance addition of the reinforcing particles with a mixture of magnesia and zirconia of suitable composition [22]. Wettability can also be increased by cleaning the reinforcement surface because the existence of firm layer of oxide on the ceramic performs impede the wetting and infiltration [23]. To overcome the problem of wetting between $\mathrm{B}_{4} \mathrm{C}$ and molten aluminum melt, titanium having flux $\left(\mathrm{K}_{2} \mathrm{TiF}_{6}\right)$ was used when the composite was produced by stir casting route. The microstructural examination of both as-cast and heat treated specimens with or without the introduction of titanium was carried out using SEM analysis. The formation of reaction layer was also examined with EDS analysis and X-ray mapping. It was found that the 
microstructural observation by high resolution field emission gun SEM (FEG-SEM), wetting improved by the formation of very thin $\mathrm{TiC}$ and $\mathrm{TiB}_{2}$ reaction layers [12].

\section{RESULTS AND DISCUSSIONS}

\section{A. Mechanical and Microstructural examination}

The investigation of mechanical behavior of a composite material is very much depends on several factors such as type of reinforcing particles, amount of reinforcement, size and shape of particles etc. Composite materials have several applications in different areas, so a proper understanding of mechanical and microstructural behavior of composite materials is very vital. In 1989 Kamat et al.[24] examined the mechanical properties of AA2024 reinforced with alumina $\left(\mathrm{Al}_{2} \mathrm{O}_{3}\right)$ particles and analyzed that with increase in $\%$ vol. fraction of alumina particles the UTS and YS of the resulting composite increased. Azim et al.[25] examined that the YS of casted composite increased while the UTS and \% elongation of the composite decreased with the addition in the \% vol. fraction of reinforcing material when AA2024 was reinforced with $\mathrm{Al}_{2} \mathrm{O}_{3}$ particles. Tee at al.[[26] manufactured aluminum- $\mathrm{TiB}_{2}$ composite material by utilizing in-situ stir casting technique. They have analysed that the yield strength and ultimate tensile strength of the resulting composite was two times that of ascast unreinforced matrix alloy but the ductility of the composite was decreased. Amirkhanlou and Niroumand[13] has produced AA356/5\% $\mathrm{SiC}_{\mathrm{p}}$ composites by varying the size of Silicon carbide particles (sizes of about $3 \mu \mathrm{m}$ and $8 \mu \mathrm{m}$ ) by incorporation of various forms of the reinforcement particles into the semi-solid highly viscous slurry and fully liquid molten melt of AA356. The authors observed that inclusion of SiC particles in the form of composite powder and casting in semi-solid state decreased the $\mathrm{SiC}_{\mathrm{p}}$ particle size, enhanced the wettability and improved the dispersion of reinforced particles in resulting composite matrix. There was a increase in the hardness values and impact energy of the composite material with a decrease in porosity.

Aigbodion and Hassan[11] has investigated the effects of $\mathrm{SiC}$ reinforcement on microstructure and mechanical behavior of as-cast aluminum matrix composite (AMC's) produced by double stir casting technique. The results revealed that, addition of $\mathrm{SiC}$ particles from 5 to $25 \mathrm{wt}$. \%, inflated the hardness and apparent porosity by $75 \%$ and $39 \%$, respectively, and a decrease in density and impact energy by $1.08 \%$ and $15 \%$ respectively was observed. The 20 wt. \% addition of SiC particles increased YS and UTS by $26.25 \%$ and $25 \%$ respectively. The 20 wt. \% addition of $\mathrm{SiC}$ particles increased YS, UTS and hardness values upto a maximum values of $79.98 \mathrm{~N} / \mathrm{mm}^{2}, 106.12 \mathrm{~N} / \mathrm{mm}^{2}$ and $67.0 \mathrm{HRB}$, respectively. They discussed that the uniform dispersion of hard and brittle reinforcement particles was attributed to the increase in strength and hardness of the ductile metallic matrix. The microscopic examination revealed a dark and white metal phases, which occurred into increase in dislocation density at the matrix-particle interfaces. The fig. below shows variation of properties and distribution of ceramic particles in the resulting composite material (Refer Fig. 1, 2, 3, 4, 5, 6).

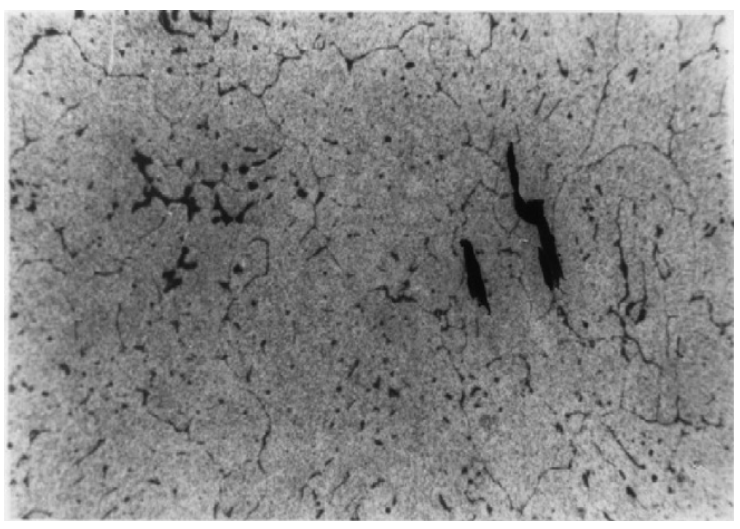

(a)

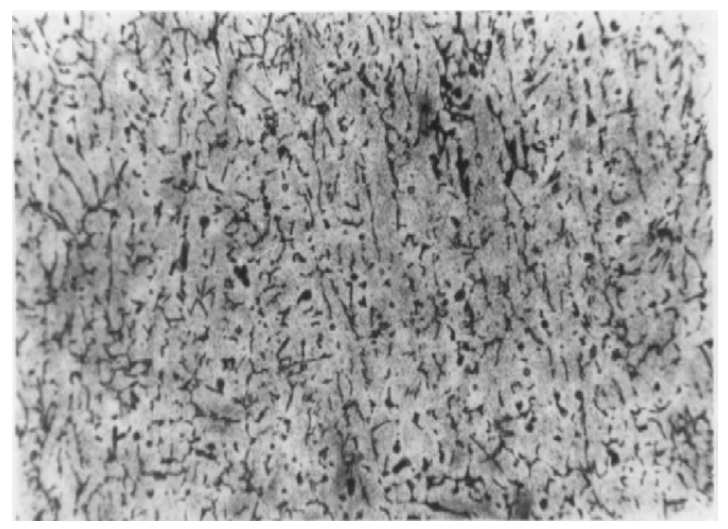

(b)

Fig. 1: (a) Micrograph of unreinforced alloy, having phase $\mathrm{FeAl}_{3} \mathrm{Si}$ (gray scripts). (b) Micrograph of reinforced alloy with $5 \%$ SiC. Showing the eutectic silicon phase and uniform dispersion of silicon carbide particles (Aigbodion and Hassan) 




(a)

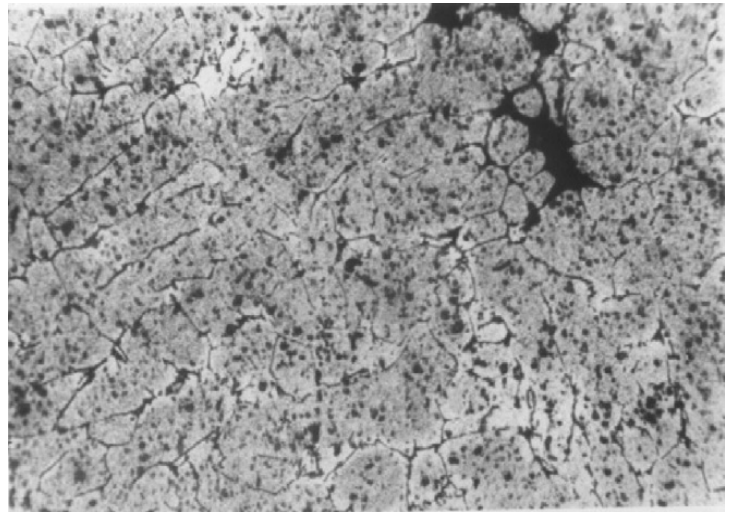

(b)

Fig. 2: (a) Micrograph of reinforced alloy with $10 \% \mathrm{SiC}$. Showing the eutectic silicon phase and uniform dispersion and some agglomeration of SiC. (b) Micrograph of reinforced alloy with 15\% SiC. (Aigbodion and Hassan)



(a)

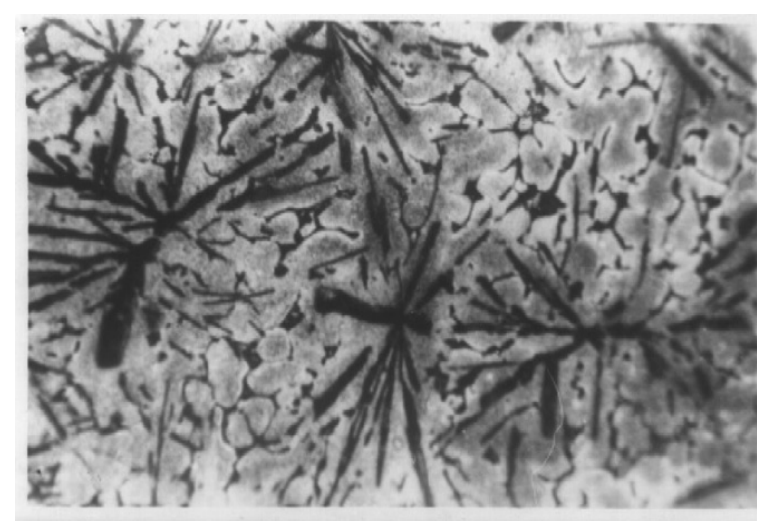

(b)

Fig. 3: (a) Optical micrograph of reinforced alloy with 20\% SiC. Dissolution of the eutectic silicon phase and more homogeneous dispersion of $\mathrm{SiC}$ particles. (b) Optical micrograph of reinforced alloy with $25 \% \mathrm{SiC}$. Showing, segregation and agglomeration of $\mathrm{SiC}$ particles (Aigbodion and Hassan)

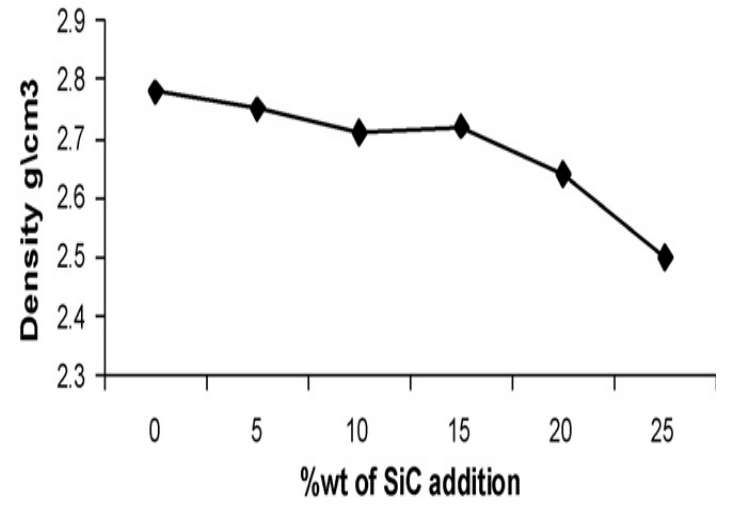

(a)



(b)

Fig. 4: (a) Variation of density versus weight $\%$ of SiC. (b) Variation of $\%$ porosity with weight $\%$ of SiC (Aigbodion and Hassan) 


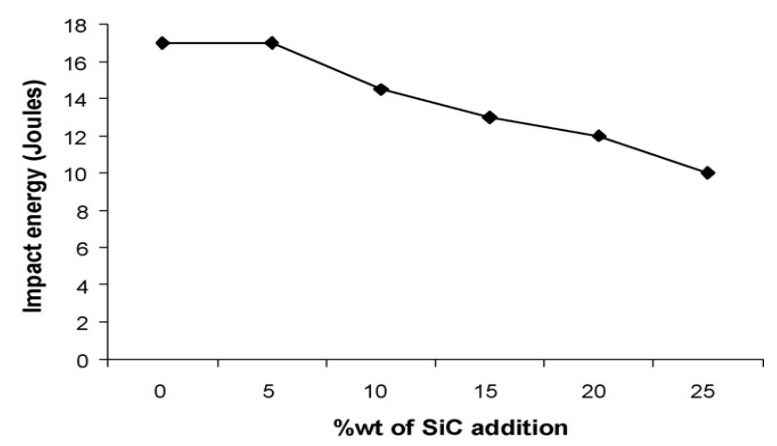

(a)

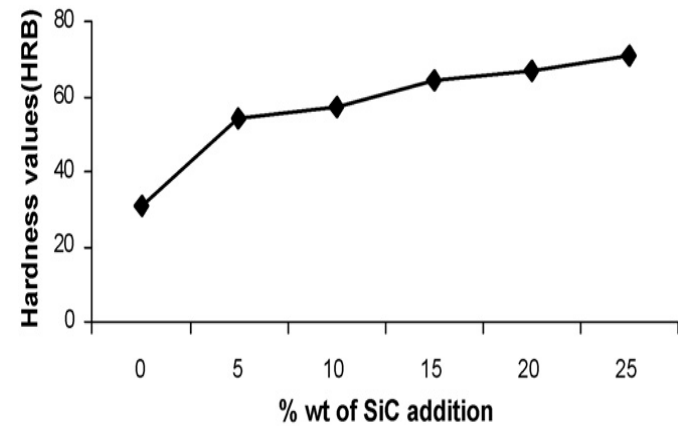

(b)

Fig. 5: (a) Impact energy versus weight $\%$ of SiC. (b) Hardness versus weight $\%$ of SiC. (Aigbodion and Hassan)

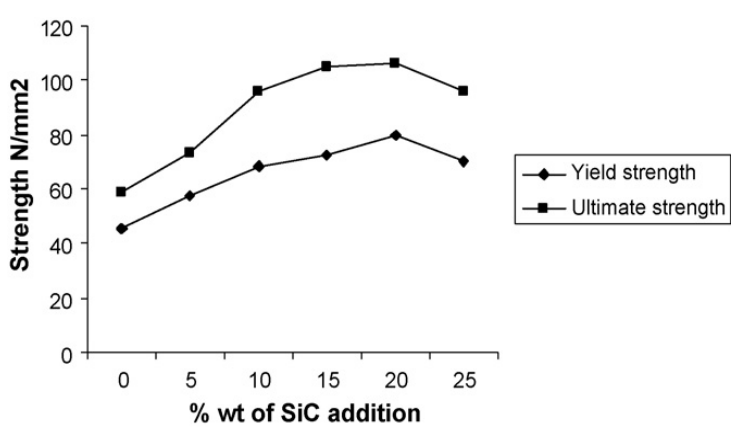

(a)

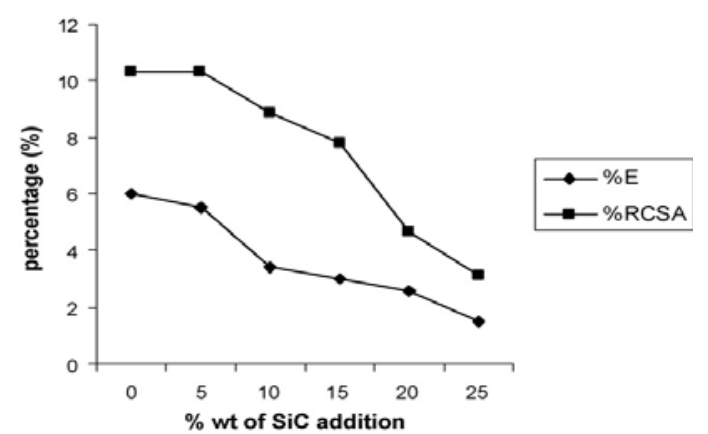

(b)

Fig. 6: (a) Graph YS and UTS versus weight \% of SiC. (b) \% E and reduction in cross-sectional area versus weight \% of SiC. (Aigbodion and Hassan)

Saravanakumar et al. (2014) [27] successfully synthesized hybrid composites of AA6063/0, 3, 6, 912 wt. $\%$ of $\mathrm{Al}_{2} \mathrm{O}_{3}$ particles +1 wt. \% of Gr. particles by employing stir casting technique. The microstructural analysis showed the impact of reinforcement particles on the grain size, dispersion of particles and agglomeration of reinforcement particles in the matrix. They observed that upto $6 \mathrm{wt}$. \% addition of alumina particles the mechanical properties viz. hardness, compression strength, impact strength, and flexural strength of the hybrid composite in as-cast and age-hardened condition shown an increased behavior. The authors found that AA6063/6 wt. \% alumina-1 wt. \% Gr. hybrid composite shown maximum values of mechanical properties (Refer Fig. 7, 8, 9, 10).
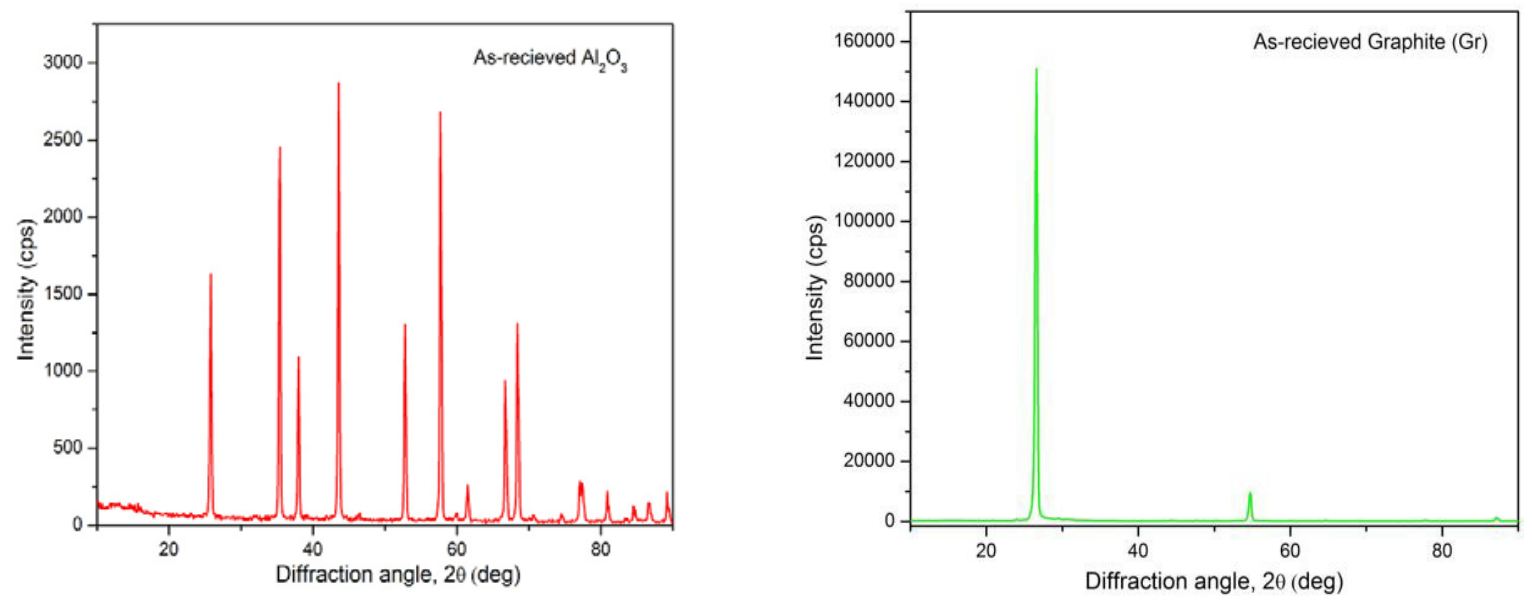

Fig. 7: XRD analysis of $\mathrm{Al}_{2} \mathrm{O}_{3}$ and Gr. Particles (as received). (Saravanakumar et al.) 


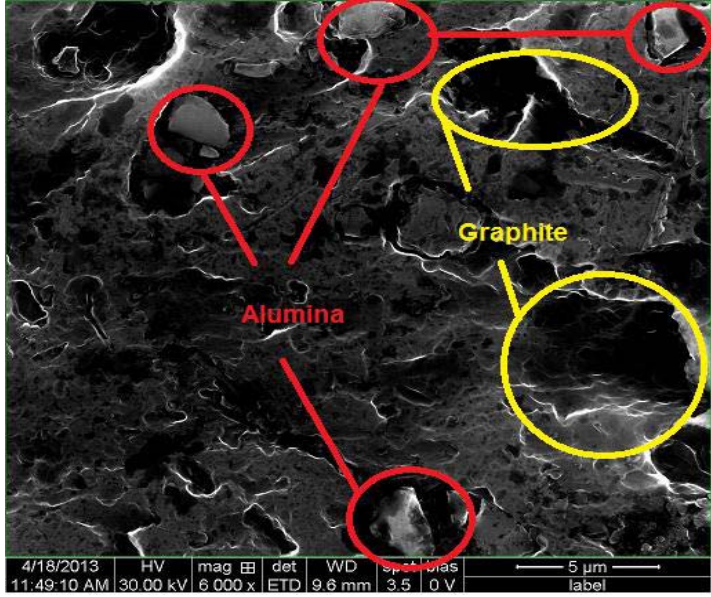

(a)

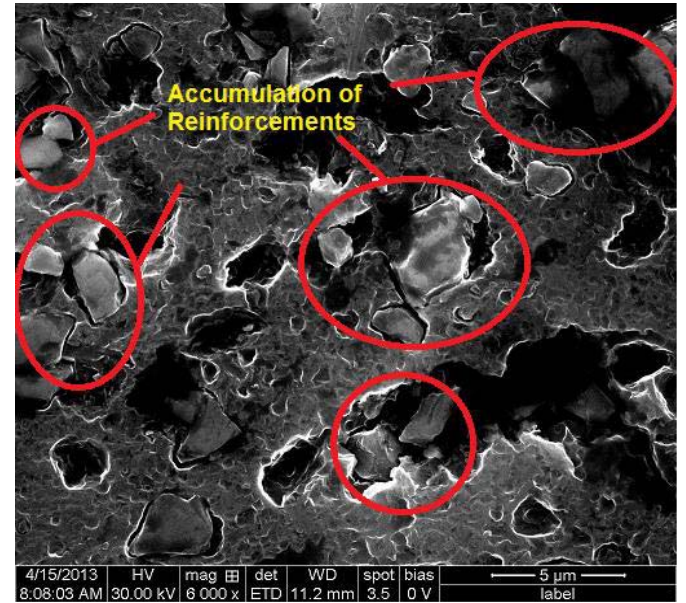

(b)

Fig. 8: SEM analysis of hybrid composite: (a) AA 6063/6 wt.\% $\mathrm{Al}_{2} \mathrm{O}_{3}-1$ wt.\% Gr. (b) AA 6063/12 wt.\% $\mathrm{Al}_{2} \mathrm{O}_{3}-1$ wt.\% Gr. (Saravanakumar et al.)

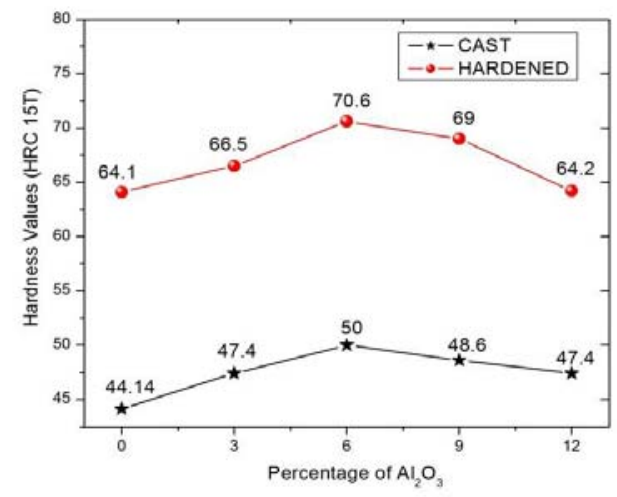

(a)

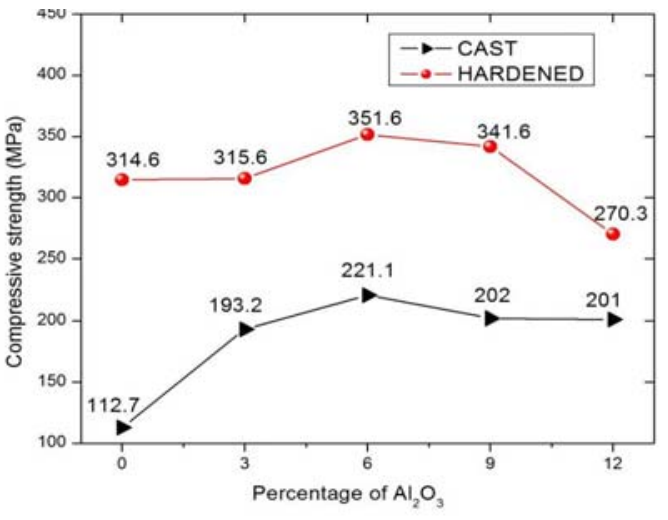

(b)

Fig. 9: (a) Hardness versus wt. $\% \mathrm{Al}_{2} \mathrm{O}_{3}-1$ wt. $\%$ Gr. Hybrid composite (b) Compressive strength versus wt. $\% \mathrm{Al}_{2} \mathrm{O}_{3}-1$ wt. $\%$ Gr. Hybrid composite (Saravanakumar et al.)

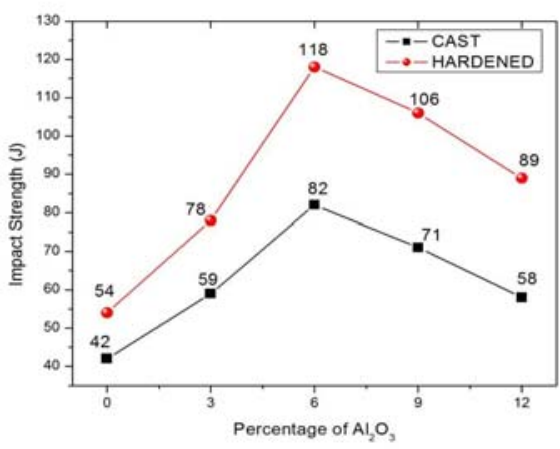

(a)

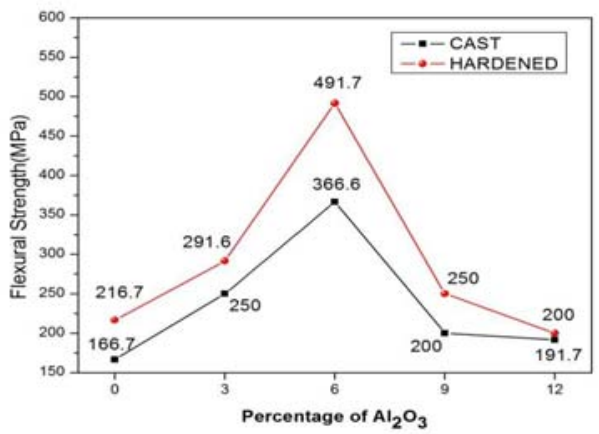

(b)

Fig. 10: (a) Impact strength versus wt. \% Al2O3p /1 wt. \% Gr. hybrid composite. (b) Flexural strength versus wt. \% A12O3p /1 wt. \% Gr. hybrid composite. (Saravanakumar et al.)

Kalaiselvan et al.[14] fabricated AA6061-T6/ $\mathrm{B}_{4} \mathrm{C}$ aluminum metal matrix composite by enhanced stir casting route by the inclusion of $\mathrm{K}_{2} \mathrm{TiF}_{6}$ as flux into the molten melt. The authors analyzed the homogeneous distribution of $\mathrm{B}_{4} \mathrm{C}$ particles in the metal matrix phase. The Vickers's microhardness of the resulting composite material was increased from $51.3 \mathrm{HV}$ to $80.8 \mathrm{HV}$ and brinell hardness from $34.4 \mathrm{BHN}$ to $58.6 \mathrm{BHN}$ by the inclusion of wt $\%$ of $\mathrm{B}_{4} \mathrm{C}$ reinforcement particles. The tensile strength increased from $185 \mathrm{MPa}$ to $215 \mathrm{MPa}$ (Refer Fig. 11, 12, 13) 

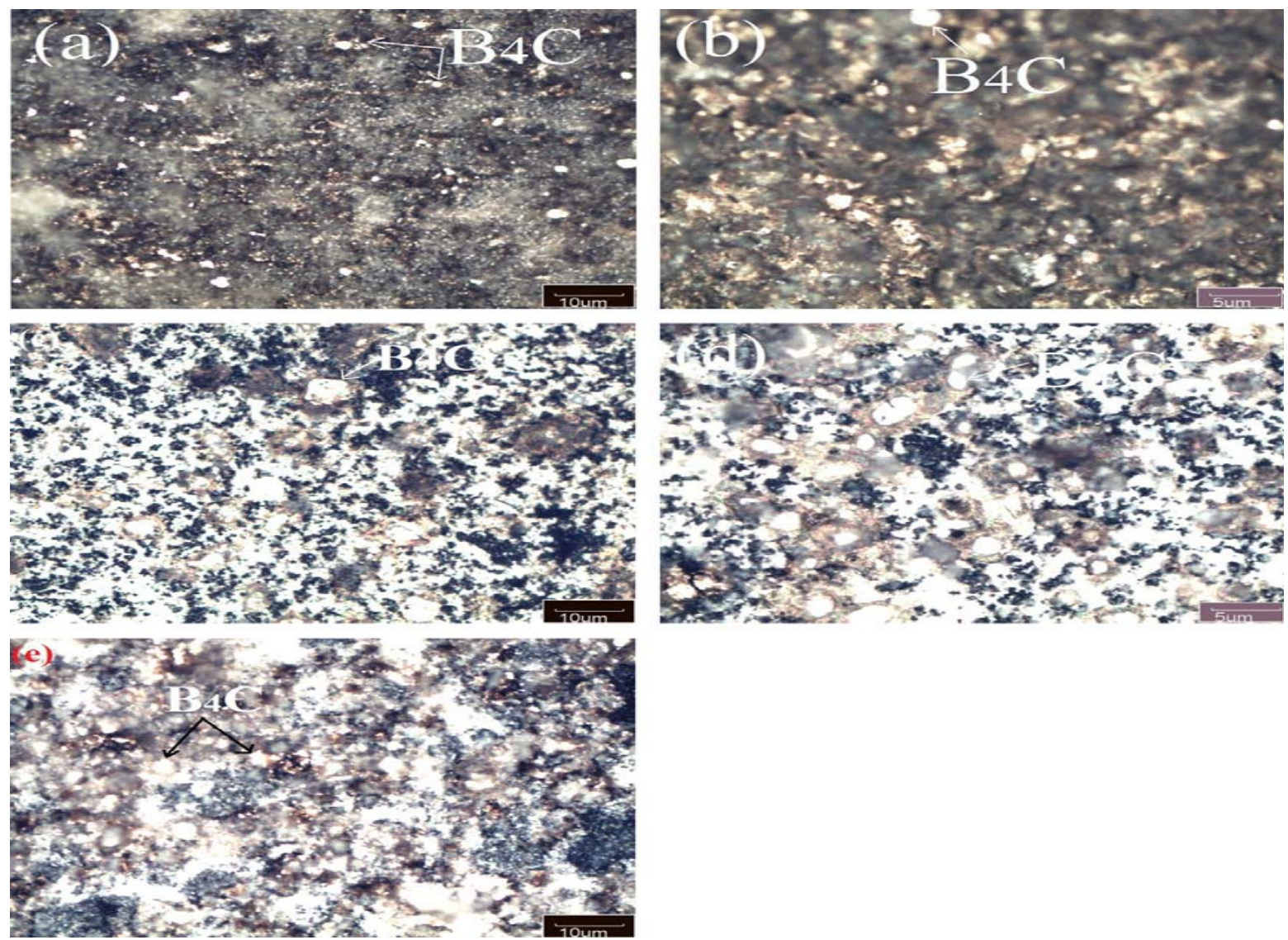

Fig. 11: Optical micrographs of the casted AA6061/ $\mathrm{B}_{4} \mathrm{C}$ AMCs reinforced with (a) $4 \% \mathrm{~B}_{4} \mathrm{C}$, (b) $6 \% \mathrm{~B}_{4} \mathrm{C}$, (c) $8 \% \mathrm{~B}_{4} \mathrm{C}$, (d) $10 \% \mathrm{~B}_{4} \mathrm{C}$, and (e) $12 \% \mathrm{~B}_{4} \mathrm{C}$ (Kalaiselvan et al.)
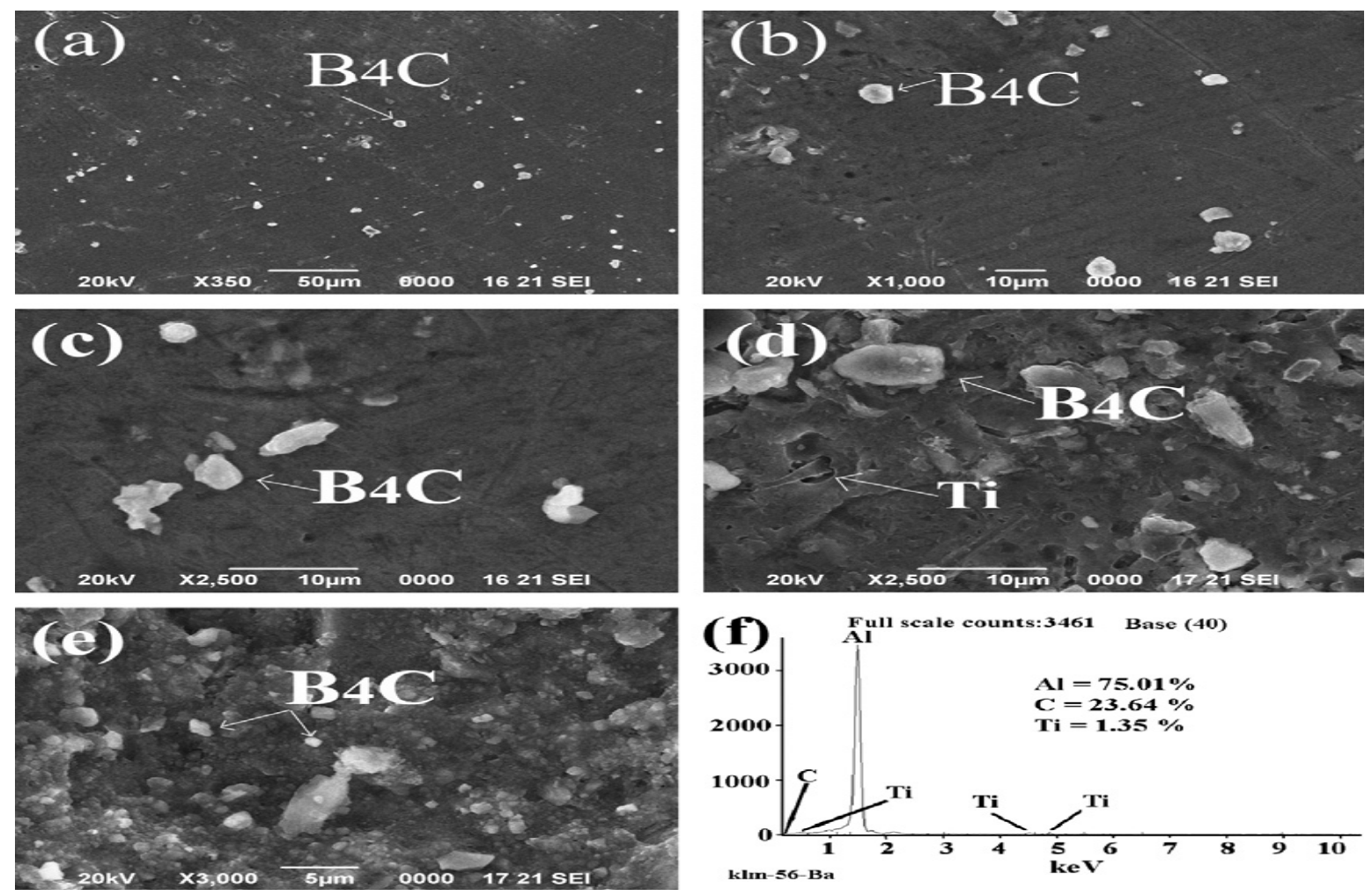

Fig. 12: SEM images of casted AA6061/B ${ }_{4} \mathrm{C}$ composites reinforced with: (a) $4 \%$ B4C, (b) $6 \%$ B4C, (c) $8 \%$ B4C, (d) $10 \%$ B4C, (e) $12 \%$ $\mathrm{B} 4 \mathrm{C}$, and (f) EDAX analysis of $10 \% \mathrm{~B} 4 \mathrm{C}$. (Kalaiselvan et al.) 


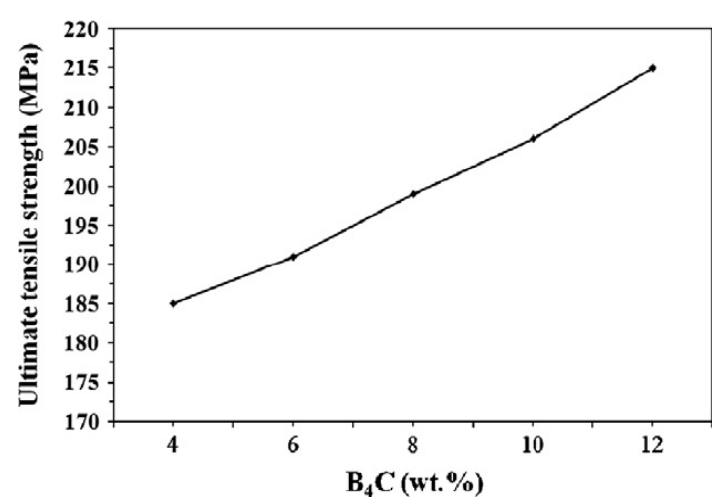

(a)

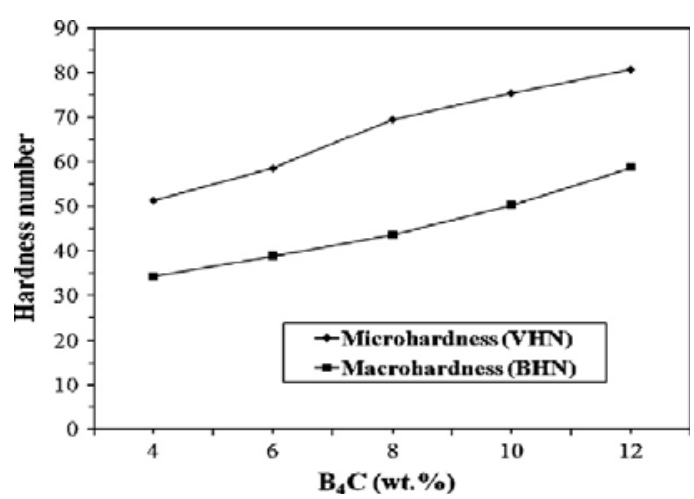

(b)

Fig. 13: (a) UTS v/s wt. \% of $\mathrm{B}_{4} \mathrm{C}$ (b). Hardness (microhardness \& macrohardness) v/s wt. \% of $\mathrm{B}_{4} \mathrm{C}$ (Kalaiselvan et al.).

Niranjan and Lakshminarayana[28] reported that hardness and ultimate tensile strength for in-situ stir casting of $\mathrm{Al} 356 / \mathrm{TiB}_{2}$ increased with the increase in mass fraction of TiB2 from $2 \%$ to $6 \%$. The maximum UTS 261.84MPa and hardness 70.88HV were reported by the authors. K.K Alaneme and A.O Aluko [10] has studied the tensile behavior and fracture toughness $\left(\mathrm{K}_{1 \mathrm{c}}\right)$ for the as-cast and age hardened AA6063 reinforced with $\mathrm{SiC}_{\mathrm{p}}$ particles $(3,6,9$ and 12 vol. \% of $\mathrm{SiCp})$ produced by employing dual-step stir casting technique. The authors examined that the tensile strength and yield strength increased with an increase in $\mathrm{SiC}_{\mathrm{p}} \mathrm{vol}$. \% for both as-cast and age hardened composites. The fracture toughness $\left(\mathrm{K}_{1 \mathrm{c}}\right)$ has increased significantly for both as-cast and age hardened composites. Zhang et al.[29] produced $\mathrm{TiB}_{2}$ matrix composites by employing high energy ball milling in-situ stir casting process and examined the microstructure and tensile behavior of the resulting composite. The microstructural study revealed that no interfacial outgrowth was observed at the interface between AA6063 alloy and $\mathrm{TiB}_{2}$ reinforcement particles. The tensile strength for the composite was found [191 MPa] 1.23 times as high as the as-cast unreinforced matrix. Habibur Rahman and Mamur Al Rashed[30] reported that maximum hardness and tensile strength were obtained at $20 \mathrm{wt} . \%$ of SiC particles reinforced with aluminum matrix, when aluminum matrix was processed with varying percentage $(0,5,10$ and $20 \mathrm{wt}$. \%) of SiC particles via stir casting technique.

Mahamani et al.[31] studied the mechanical and wear behavior of $\mathrm{AA} 6061-\mathrm{TiB}_{2} / \mathrm{ZrB}_{2}$ in-situ metal matrix composite. Experimental examination revealed that addition of ceramic particles increased the mechanical properties. Fracture surface investigations were also carried out to observe the mode of failure. Bosi et al.[32] produced metal matrix composites reinforced with $\mathrm{AA} 6061 / 10 \% \mathrm{Al}_{2} \mathrm{O}_{3}, \mathrm{AA} 6061 / 20 \% \mathrm{Al}_{2} \mathrm{O}_{3}$ and $\mathrm{AA} 2618 / 20 \%$ $\mathrm{Al}_{2} \mathrm{O}_{3}$. The microstructural and fatigue analysis was carried out using SEM/OM and EDS. The authors concluded that in high cycle fatigue regime; the composite material exhibited better resistance than unreinforced matrix alloy at low stress. They also observed that composite resistance to low cycle fatigue was less satisfactory due to coarser reinforcement. Gurusamy and Balasivanandha parbu[33] studied the mechanical behavior of AA356/SiC composite manufactured by squeeze casting process using the stir casting route. Microstructural examination showed homogeneous dispersion of Silicon carbide particles into the matrix alloy and grain refinement of the resulting composite material. They observed that squeeze casting at pressure of 100MPa produced sound aluminum matrix composite with excellent tensile and hardness properties.

G.M Vecchia et al.[34] carried out the fracture mechanism and tensile behavior of aluminum matrix composite reinforced with $30 \mathrm{vol}$. \% of SiC. They observed that fracture toughness and tensile behavior of the composite increased with the high vol. \% of the reinforcement particles as compared to the unreinforced aluminum alloy matrix. Nourouzi et al.[35] fabricated $\mathrm{Al}_{-} \mathrm{Al}_{2} \mathrm{O}_{3}$ composites by injecting the $\mathrm{Al}_{2} \mathrm{O}_{3}$ particles in four different forms into the molten metal matrix. The SEM and OM examination of the composite showed a homogeneous dispersion of $\mathrm{Al}_{2} \mathrm{O}_{3}$ reinforcement agents into the al matrix alloy. The mechanical testing revealed that maximum values of hardness, yield strength and impact energy were observed with values of 78.7BHN, $142 \mathrm{MPa}$ and 8.2J respectively. Das et al.[36] studied the mechanical behavior of al-matrix reinforced with angular and spherical shaped reinforcement particles. The authors studied that the inclusion of both spherical and angular shaped particles significantly enhanced the UTS, elastic modulus and $0.2 \%$ proof stress but decreased the ductility compared with the unreinforced matrix alloy. Vedani et al.[37] investigated that the inclusion of $10 \mathrm{vol}$ \% $\mathrm{SiC}$ particles to AA6061 matrix increased the young's modulus and peak frequency by $24.898 \%$ and $7.38 \%$ respectively for the resulting composite. 


\section{B. Tribological examination}

The matrix composites of aluminum alloy reinforced with various ceramic materials like $\mathrm{SiC}, \mathrm{B}_{4} \mathrm{C}, \mathrm{TiC}$, $\mathrm{Al}_{2} \mathrm{O}_{3}$ and $\mathrm{TiB}_{2}$ etc. have been widely used in many applications (semiconductor industry, bearings, heat exchangers, brushes, and contact strips etc.) due to their elevated specific strength and superior wear resistant properties. The interfacial bond strength, normal load, sliding distance, surface finish, environmental conditions, shape and size of ceramic particles and $\mathrm{wt} \%$ of the reinforcement are the various parameters which influence the wear behavior of the metal matrix composites. Wilson and Alpas[38] tested unlubricated dry slippery wear behavior at high temperature of $\mathrm{AA} 356 / \mathrm{SiC}, \mathrm{AA} 356 /\left(\mathrm{SiC}+\right.$ graphite), and $\mathrm{AA} 6061 / \mathrm{Al}_{2} \mathrm{O}_{3}$ composite. They examined that the mixing of reinforcement particles enhance the wear property of the composite material significantly at elevated temperature compared to aluminum matrix alloy. The authors observed that $\mathrm{SiC}$ being more effective than $\mathrm{Al}_{2} \mathrm{O}_{3}$. They found that at higher temperature ( $\mathrm{SiC}+$ graphite) hybrid composite have shown better resistance to severe wear compared to $\mathrm{AA} 356-\mathrm{SiC}$ and $\mathrm{AA} 6061-\mathrm{Al}_{2} \mathrm{O}_{3}$ composite materials. Tee at el.[26]

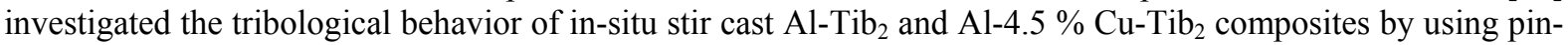
on-disc wear tester and analysed that rate of wear for both the composite material lowered with increase in $\%$ vol. fraction of $\mathrm{Tib}_{2}$. They found that Al-Tib 2 composite has shown higher resistance to wear than the Al-4.5\% $\mathrm{Cu}-\mathrm{Tib}_{2}$ composite material. The authors have noted that the volume loss with increase in sliding distance in composite material increases at slower rate as compared to pure aluminum matrix alloy. Kok[39] fabricated AA 2024 composite reinforced with alumina $\left(\mathrm{Al}_{2} \mathrm{O}_{3}\right)$ particles by vortex method and studied the wear properties. He found that wear properties were very much affected by the sliding distance, $\mathrm{wt} \%$ of $\mathrm{Al}_{2} \mathrm{O}_{3}$, size of ceramic particles and abrasive grit size. The volumetric loss for composite material was very low as compared to pure aluminum alloy. The author found that the volumetric loss lowered with increase in $\mathrm{wt} \%$ of $\mathrm{Al}_{2} \mathrm{O}_{3}$ and particle size and the wear losses increased with increase in both sliding distance and grit size.

Natarajan et al.[40] studied the pin-on-disc dry slippery wear behavior of fabricated in-situ AA6063/Tib 2 composite material at applied loads of $9.8 \mathrm{~N}, 19.6 \mathrm{~N} \& 29.4 \mathrm{~N}$ at different temperature $(100,200$ and $300 \mathrm{deg}$. celsius) and at room conditions for comparison. The authors studied that wear rate lowered with increase in wt $\%$ of $\mathrm{TiB}_{2}$, while the wear rate increased with increase in the applied load. At elevated temperature the test revealed that the resistance to wear of composite material was greater than those for the unreinforced Al-alloy matrix at all test temperatures (Refer Fig. 14, 15, 16, 17, 18, 19, 20, 21, and 22).

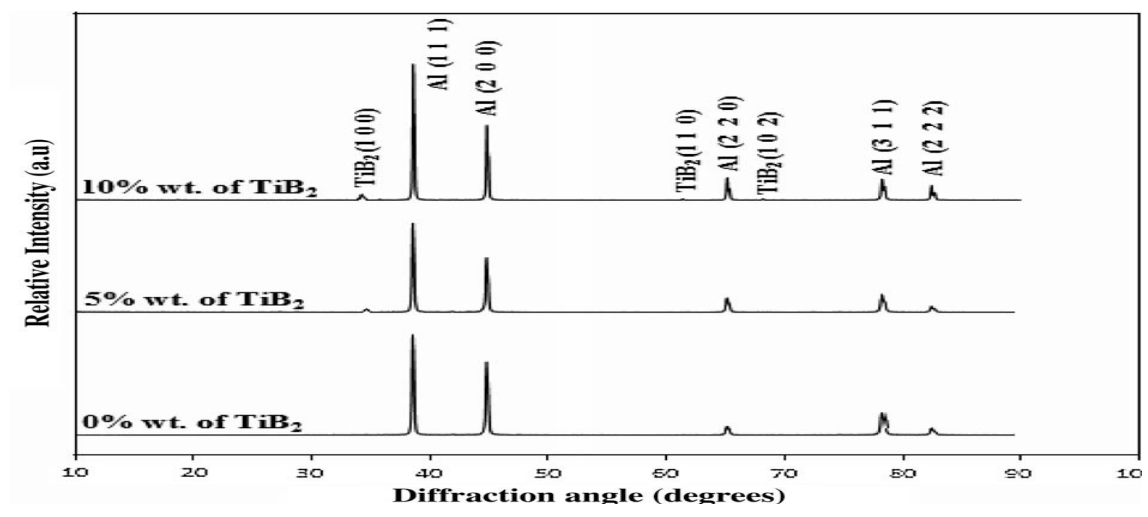

Fig. 14: XRD pattern of the processed composites. (Natarajan et al.)

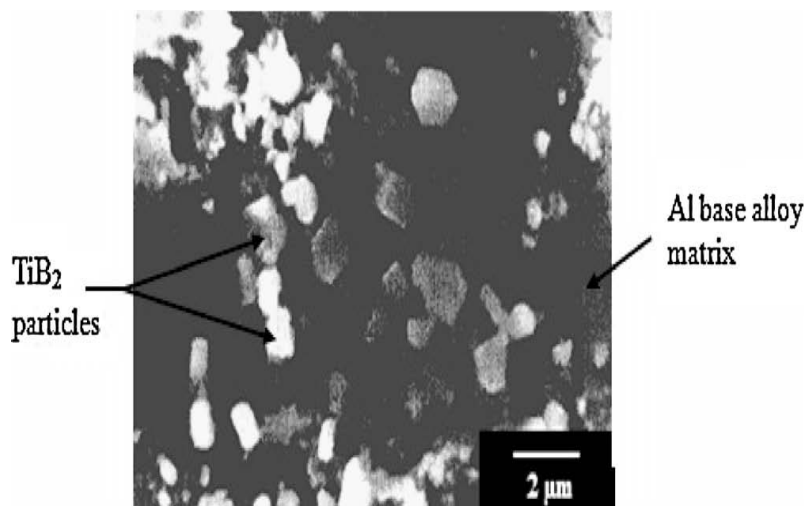

(a)

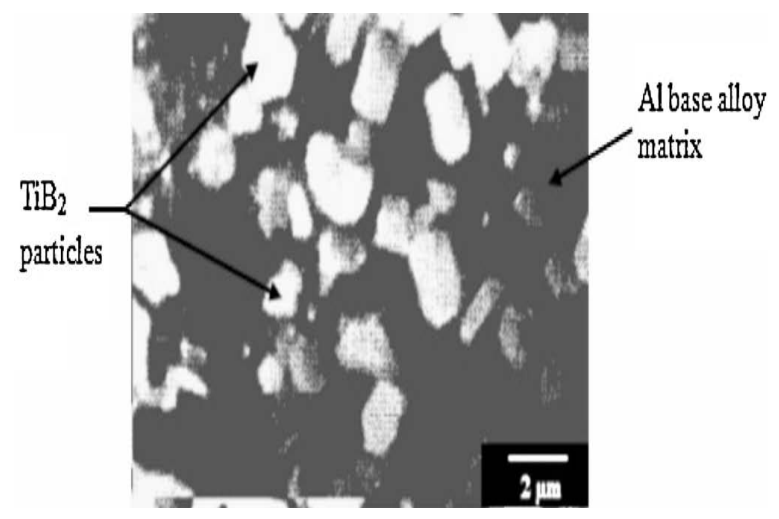

(b)

Fig. 15: (a) SEM image of $\mathrm{Al} 6063 / 5 \% \mathrm{TiB}_{2}$ composite. (b) SEM image of $\mathrm{Al} 6063 / 10 \% \mathrm{TiB}_{2}$ composite. (Natarajan et al.) 

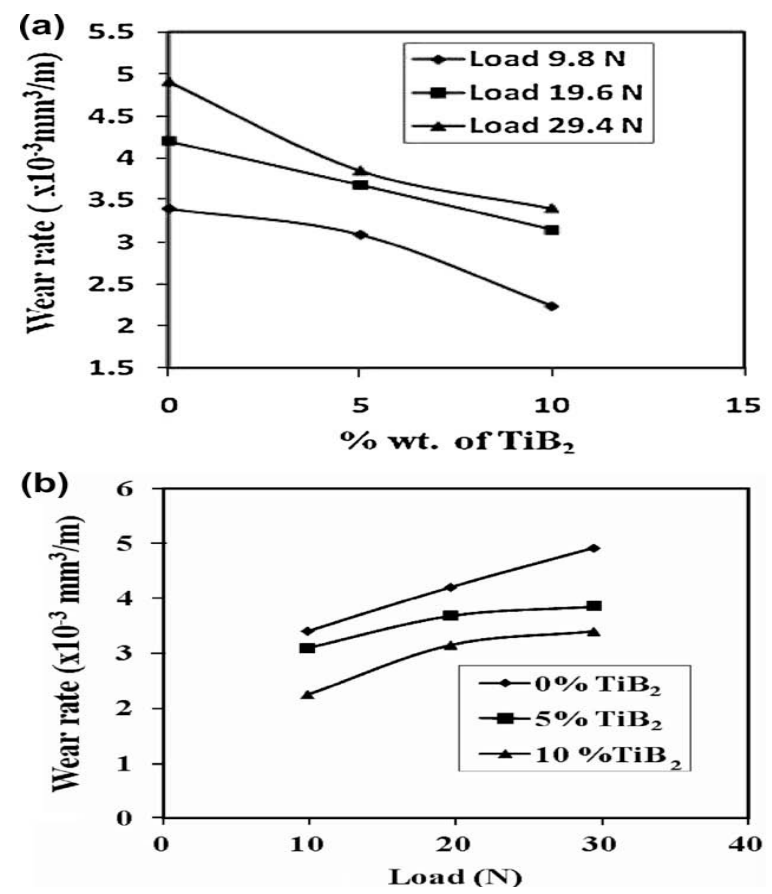

Fig. 16: (a) Wear rate v/s wt. $\%$ of $\mathrm{Al} / \mathrm{TiB}_{2}$ composite (b) wear rate v/s applied load of $\mathrm{Al} / \mathrm{TiB}_{2}$ composite (Natarajan et al.)
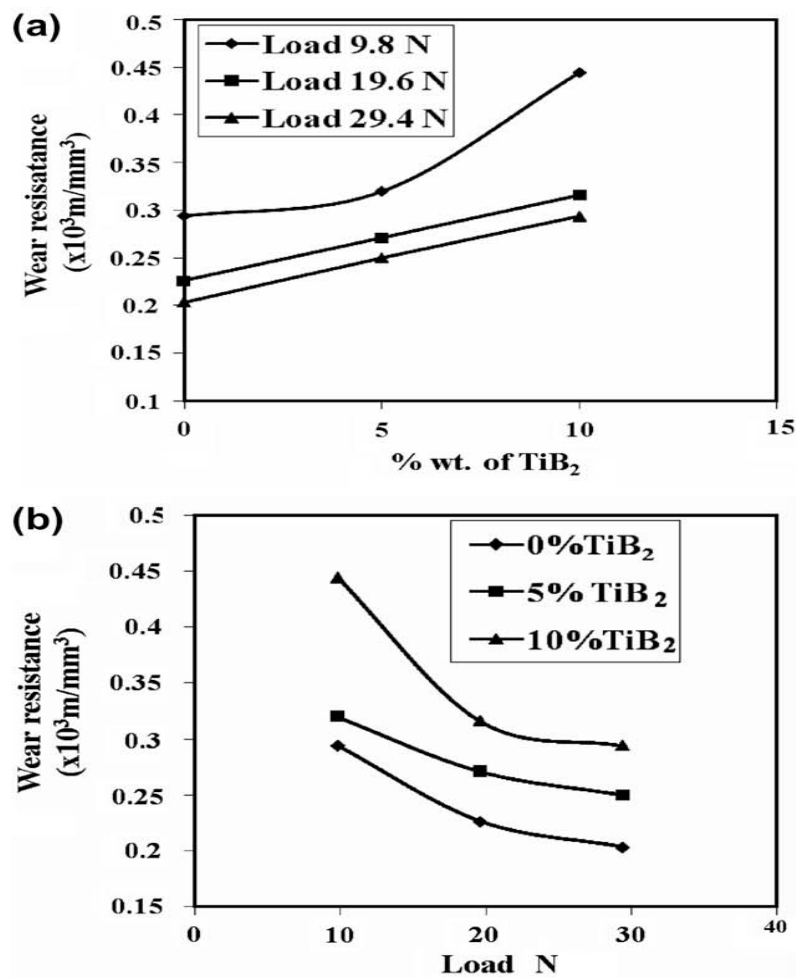

Fig. 17: (a) Wear resistance v/s wt. \% of $\mathrm{Al} / \mathrm{TiB}_{2}$ composite (b) Wear resistance $\mathrm{v} / \mathrm{s}$ applied load of $\mathrm{Al} / \mathrm{TiB}_{2}$ composite (Natarajan et al.) 


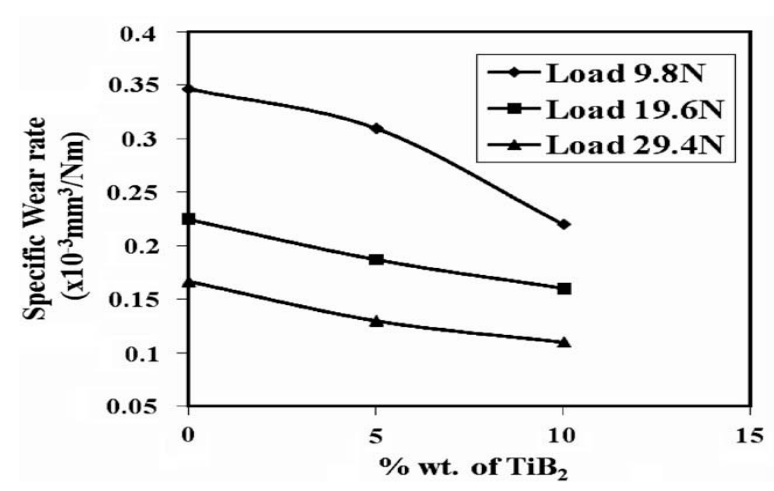

(a)

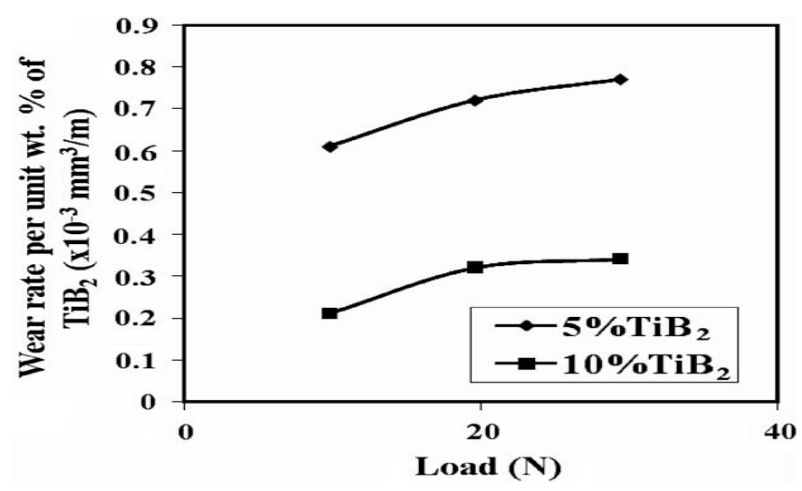

(b)

Fig. 18: (a) Specific wear v/s wt. \% of $\mathrm{TiB}_{2}$. (b) Wear rate per unit wt. $\%$ of $\mathrm{TiB}_{2}$ particles v/s applied load. (Natarajan et al.)
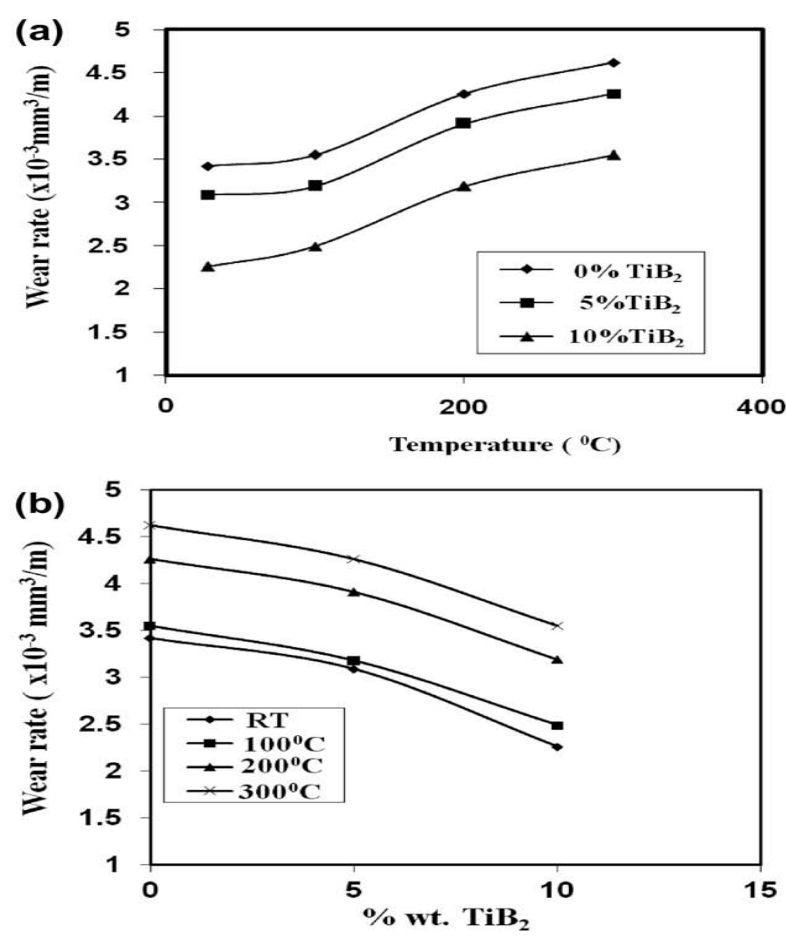

Fig. 19: (a) Variation of wear rate v/s temperature, and (b) Variation of wear Rate v/s wt. \% of $\mathrm{TiB}_{2}$. (Natarajan et al.)



(a)

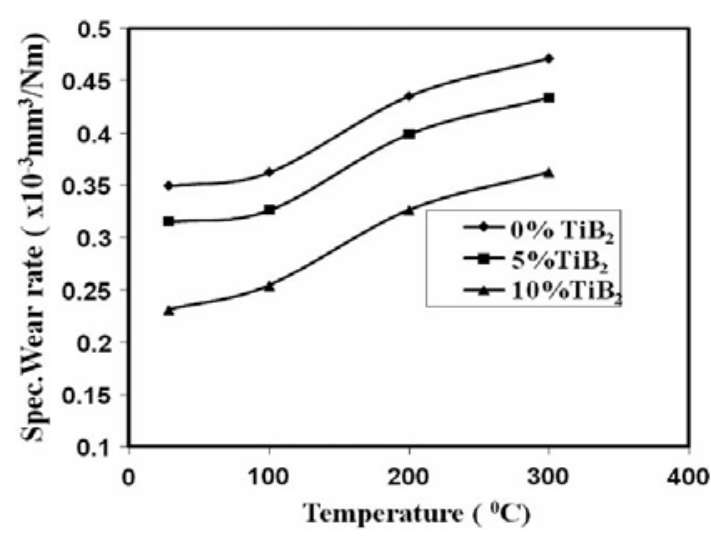

(b)

Fig. 20: (a) Variation of wear resistance with temperature. (b) Variation of specific wear resistance with temperature. (Natarajan et al.) 

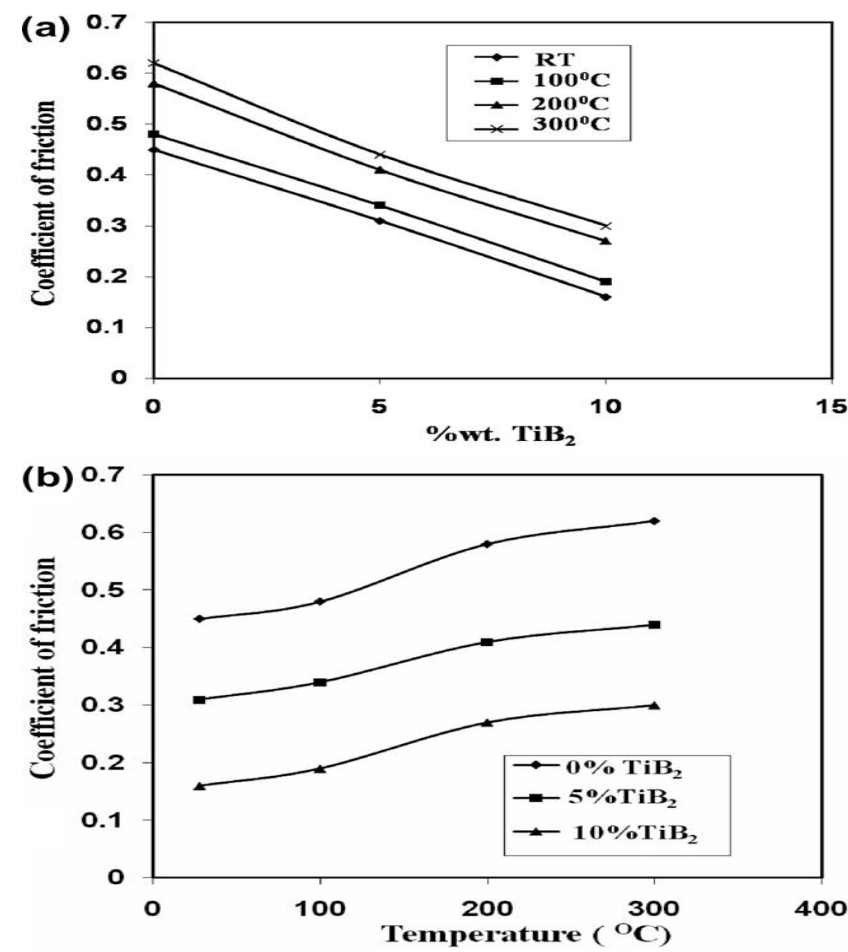

Fig. 21: (a) Variation of coefficient of friction v/s wt. $\%$ of $\mathrm{TiB}_{2}$ (b) Variation of coefficient of friction v/s temperature. (Natarajan et al.)

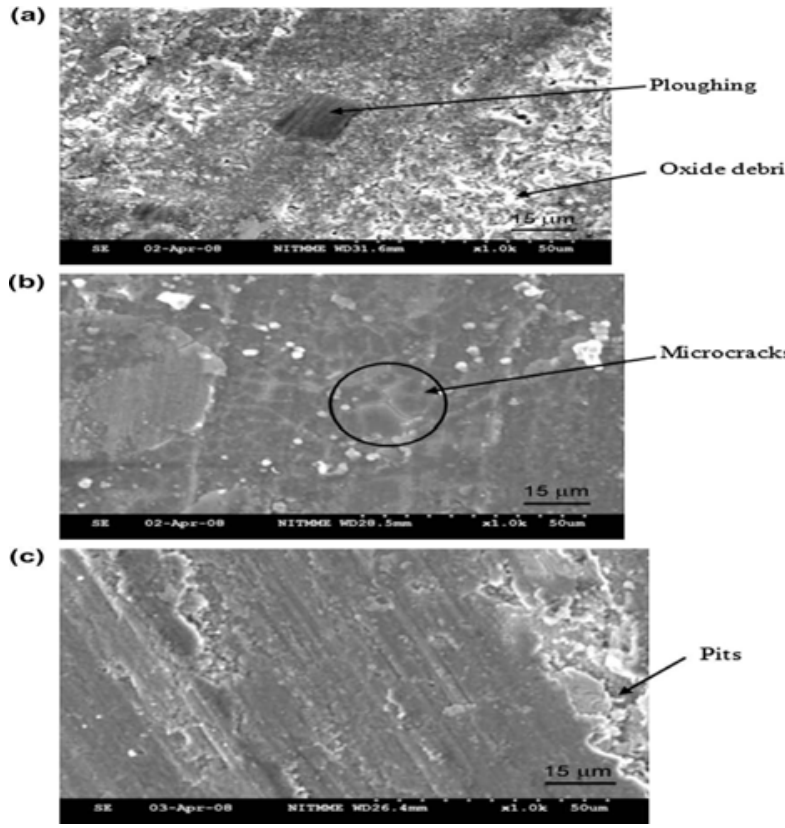

(a)

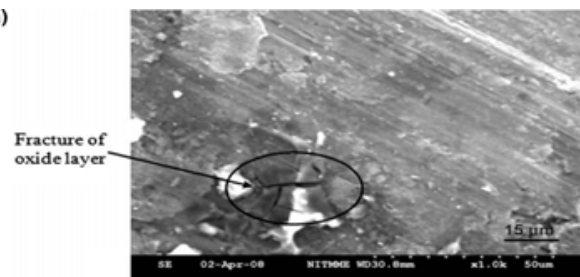

(b)

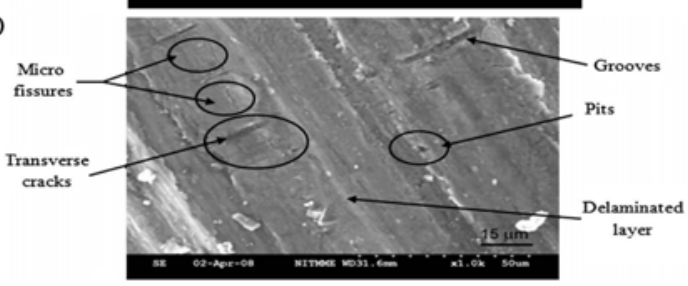

(c)

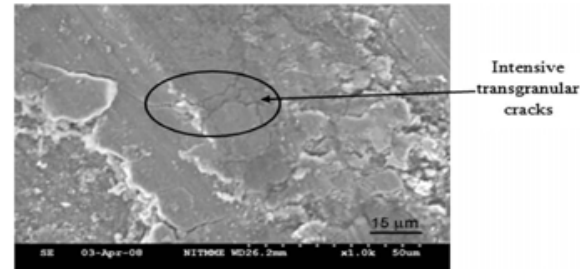

(b)

Fig. 22: (A) SEM images of the worn out surfaces of AA6063 alloy and AA6063/TiB 2 composite sliding at temperature of $100{ }^{0} \mathrm{C}$ : (a) AA6063, (b) AA6063/5\% $\mathrm{TiB}_{2}$, (c) AA6063/10\% TiB 2 . (B) SEM images of the worn out surfaces of AA6063 and AA6063/TiB2 composite sliding at $200{ }^{\circ} \mathrm{C}$ : (a) AA6063, (b) AA6063/5\% $\mathrm{TiB}_{2}$, (c) AA6063/10\% $\mathrm{TiB}_{2}$. (Natarajan et al.)

Gopalakrishnan and Murgan[41] synthesized AA6061/TiC $\mathrm{p}_{\mathrm{p}}$ composite by employing enhanced stir casting technique by varying the volume fractions of $\mathrm{TiC}_{\mathrm{p}}$. Their analysis found significant improvement in the specific strength and resistance to wear of the composite material. The dry slippery wear performance using pin-on-disc wear and friction monitor revealed that wear loss increased linearly with normal load, but increased at a very lower rate with increased volume fractions of $\mathrm{TiC}_{\mathrm{p}}$. They found that the composites produced by enhanced stir casting technique have very less wear loss in terms of volume loss when compared with tests conducted on Al$\mathrm{TiC}_{\mathrm{p}}$ produced by in-situ technique (Refer Fig. 23 and 24). 

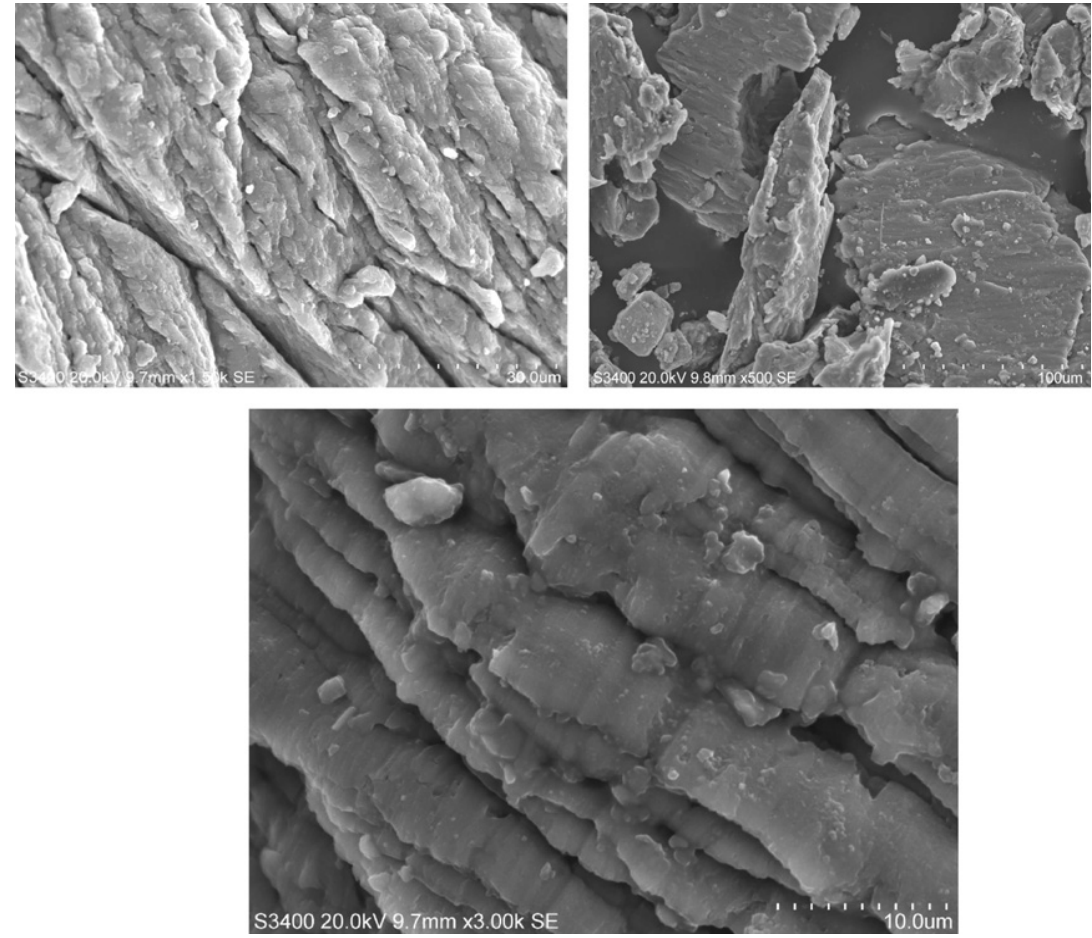

Fig. 23: SEM images of Al/TiCp composite manufactured by enhanced stir casting process. (Gopalakrishnan and Murgan)

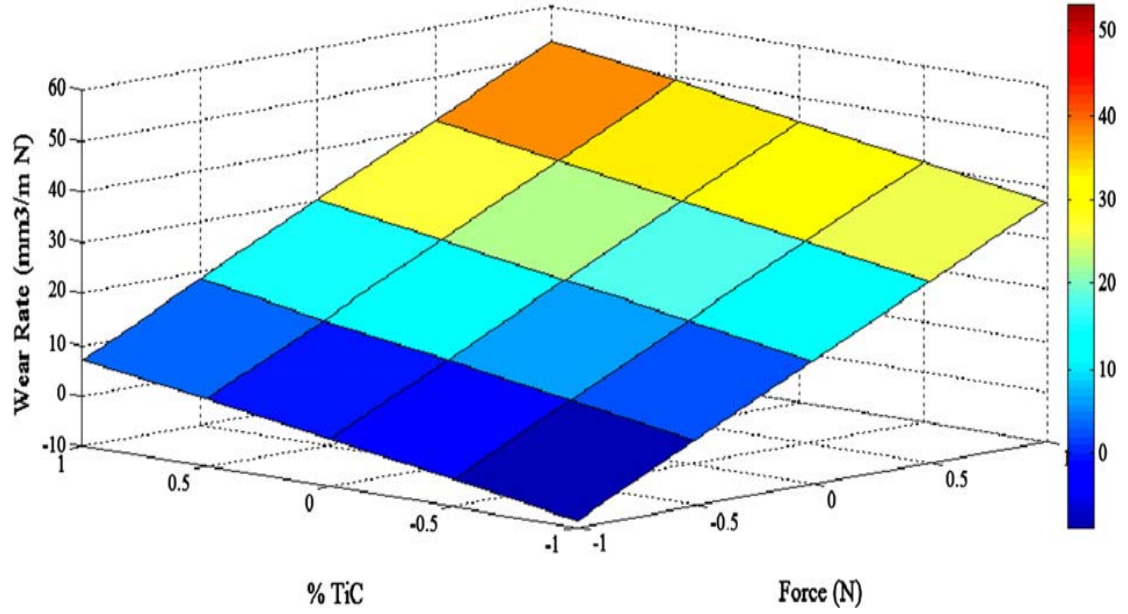

Fig. 24: Interaction plot (Response surface graph) showing effect of wt. \% of TiC and Normal force on specific wear rate. (Gopalakrishnan and Murgan)

Suresh and Shenbag[42] studied that the addition in weight fraction $(0 \%, 4 \%, 8 \%$ and $12 \%)$ of $\mathrm{TiB}_{2}$ in AA6061 improved the wear resistance of composite material. Bharath et al.[33] produced AA6061 composite reinforced with $\mathrm{Al}_{2} \mathrm{O}_{3}$ particles (varying from 0-12 wt \%) using stir casting technique. The authors conducted dry sliding wear test of the composite specimens and found that composite specimen with AA6061/12 wt\% $\mathrm{Al}_{2} \mathrm{O}_{3}$ has minimum weight loss when compared as-cast unreinforced AA6061. Radha and Vijayakumarb[43] examined the wear behavior of AA6061 reinforced with Silicon carbide and grapheme nano particles composite fabricated by stir casting process. They found a remarkable enhancement in mechanical and tribological properties of the composite. The authors found that wear rate and friction coefficient decreased accordingly with the increase in $\mathrm{wt} \%$ of grapheme nano particles. Yogesh et al.[9] investigated the dry slippery wear analysis of AA6061 based composites reinforced separately with red mud, $\mathrm{SiC}$ and $\mathrm{Al}_{2} \mathrm{O}_{3}$ particles using pin-on-disc tribometer. They examined that wear rate decreased with increase in $\mathrm{wt} \%$ of $\mathrm{SiC}$ and $\mathrm{Al}_{2} \mathrm{O}_{3}$ in the matrix, but the wear rate of red mud reinforced composite decreased upto $7.5 \mathrm{wt} \%$ only and increased beyond $7.5 \mathrm{wt} \%$. This happened due to increased viscosity of AA6061 composite and because of agglomeration effects in the composite matrix. The $7.5 \mathrm{wt} \%$ red mud reinforced composite nearly had constant wear rate throughout the dry slippery wear examination. The authors also concluded that AA6061 composite with $7.5 \mathrm{wt} \%$ had the maximum value of hardness among the different produced composites with red mud as reinforcement. 


\section{CONCLUSIONS}

A significant amount of work has been devoted to the research and development of aluminum matrix composites in recent years. Various techniques like stir casting, powder metallurgy and in-situ formation have been developed and applied to the processing of AMCs. Key factors influencing the performance of the AMCs are the shape, size, distribution of the reinforcements, bonding strength at matrix-reinforcement interface and the cost effective method of processing. The present review derived from the prior works carried out reaches to a number of outcomes listed here: (i) The liquid metal processing technique known as Stir casting technique is well suited, economical and can be successfully employed to produce Al-matrix composite materials possessing desired mechanical, microstructural and wear properties. (ii) Aluminum and its alloys reinforced with ceramic agents exhibited significant improvement in microstructural, mechanical and tribological performances. (iii) The mechanical properties such as UTS, YS, hardness, fracture toughness increased significantly while the ductility is reduced with the addition of $\mathrm{SiC}, \mathrm{B}_{4} \mathrm{C}, \mathrm{Al}_{2} \mathrm{O}_{3}, \mathrm{TiC}, \mathrm{TiB}_{2}$, red mud etc. (iv) The resistance to wear of fabricated AMCs increased with increasing $\mathrm{wt} \%$ and decreasing the size of particles of ceramic agents. (v) The above review showed that wear rate mostly depends on applied load, sliding speed and sliding distance and sliding distance is the most influencing parameter. (vi) For aluminum matrix composites reinforced with organic reinforcements, very limited amount of research work has been carried out. Aluminum matrix alloy reinforced with organic reinforcements have shown significant increase in mechanical and tribological properties. This provides scope for further investigation in the field of organic reinforced metal matrix composites. (vii) Nano sized ceramic particles and hybrid ceramic particles have remarkably increased the mechanical and wear properties of the composite material. A limited amount of work has been reported in literature in this field. This extends further opportunity for research in this domain. (viii) The modified dual step stir casting techniques for enhancing the dispersion of ceramic particles into the matrix phase and minimizing the chances of agglomeration in metal matrix composites has been reported by a few authors. This reorganized technique has required more work to be carried out in this domain.

\section{REFERENCES}

[1] Tokaji, K,. 2005, "Effect of stress ratio on fatigue behavior in SiC particulate-reinforced aluminium alloy composite", Fatigue Fract. Eng. Mater. Struct., 28(6), pp. 539-45.

[2] Lopez, V.H., Scoles, A., Kennedy, A.R., 2003, "The thermal stability of TiC particles in an Al7 wt. \% Si alloy", Mater. Sci. Eng., A356, pp. 316-25.

[3] Khan, K.B., Kutty, T.R.G., Surappa, M.K., 2006, "Hot hardness and indentation creep study on Al-5\% Mg alloy matrix-B $\mathrm{B}_{4} \mathrm{C}$ particle reinforced composites", Mater. Sci. Eng., A 427, pp. 76-82.

[4] Adamiak, M., 2006, "Selected properties of the aluminium alloy base composites reinforced with intermetallic particles", J. Achievements Mater. Manuf. Eng., 14(1-2).

[5] Hashim, J., Looney, L., and Hashmi, M.S.J., 1999, J. Mater. Process. Technol. 92-93, 1.

[6] Ray, S., 1969, M.Tech Dissertation, (Indian Institute of Technology, Kanpur, 1969).

[7] LUO, A., 1995, Metall. Mater. Trans, A 26A (1995) 2445.

[8] Saravanan, R.A., and Surappa, M.K., 2000, Mater. Sci. Engg. A 276 (2000) 108.

[9] Singla, Y.K., Chhibber, R., Bansal, H. and Kalra, A., 2015, "Wear Behavior of Aluminum Alloy 6061-Based Composites Reinforced with SiC, Al2O3, and Red Mud: A Comparative Study”, JOM, vol. 67, pp. 2160-2169.

[10] Alaneme, K.K., Aluko, A.O., 2012, "Fracture toughness $\left(\mathrm{K}_{1 \mathrm{c}}\right)$ and tensile properties of as-cast and age-hardened aluminium (6063)silicon carbide particulate composites", Scientia Iranica A, 19 (4), pp. 992-996.

[11] Aigbodion, V.S., and Hassan, S.B., 2007, "Effects of silicon carbide reinforcement on microstructure and properties of cast $\mathrm{Al}-\mathrm{Si}-$ $\mathrm{Fe} / \mathrm{SiC}$ particulate composites", Materials Science and Engineering A, 447, pp. 355-360.

[12] Toptan, F., Kilicarslan, A., Karaaslan, A., Cigdem, M., and Kerti, I., 2010, "Processing and microstructural characterisation of AA 1070 and AA 6063 matrix $\mathrm{B}_{4} \mathrm{C}_{\mathrm{P}}$ reinforced composites", Materials and Design, 31, S87-S91.

[13] Amirkhanlou, S., and Niroumand, B., 2010, "Synthesis and characterization of 356-SiCp composites by stir casting and compocasting methods", Trans. Nonferrous Met. Soc. China, 20, S788-S793.

[14] Kalaiselvan, K., Murugan, N., and Parameswaran, S., 2011, "Production and characterization of AA6061-B 4 C stir cast composite", Materials and Design, 32, pp. 4004-4009.

[15] Harnby, N., Edward, M.F., and Nienow, A.W., 1985, Mixing in Process Industries, (Butterworths, London, 1985).

[16] Girot, F.A., Albingre, L., Quenisset, J.M., and Naslain R., 1987, J. Met. 39 (1987) 18.

[17] Zhou, W., and Xu, Z.M., 1997, J. Mater. Proc. Techn. 63 (1997) 358.

[18] Rohatgi, P., 1988, Modern Casting April (1988) 47.

[19] Laurent, V., Jary, P., and Regaiiond, G., 1992, J. Mater. Sci. 27(27) (1992) 4447.

[20] Mortensen, A., 1988, "Mechanical and Physical Behaviors of Metals and Ceramic Compounds", (Riso National Laboratory, Roskilde, Denmark, 1988) p. 141.

[21] Pai, B.C., Satyanarayana, K.G., and Robi, P., 1992, J. Mater. Sci. Lett. 11 (1992) 779.

[22] Sundararajan, S., Mahadevan, R., and Dwarakadasa, E.S., 1995, "Tenth International Conference on Composite Materials", II. Metal Matrix Composites (Woodhead Publishing Limited, 1995) p. 831.

[23] Cirakoglu, M., Toy, C., Tekin, A., and Scott, W.D., 1997, Ceram. Intern. (UK) 23(2) (1997) 115.

[24] Kamat, S.V., Hirth, S.P., and Mehrabin, R.M., 1989, "Mechanical properties of particulate-reinforced aluminum-matrix composites", Acta Metallurgy, 37, p. 2395

[25] Abdel-Azim, A.N., Kassem, M.A., El-Baradie, Z.M., and Waly, M., 2002, "Structure and properties of short alumina fibre reinforced AlSi18CuNi produced by stir casting", Materials Letters 56, pp. 963-969.

[26] Tee, K.L., Lu, L., and Lai, M.O., 1999, "Synthesis of in situ Al-TiB2 composites using stir cast route", Composite Structures 47, pp. 589-593.

[27] Saravanakumara, A., Sasikumar, P., and Sivasankaranc S., 2014, "Synthesis and mechanical behavior of AA 6063-x wt. \% Al2O3-1\% $\operatorname{Gr}(\mathrm{x}=3,6,9$ and 12 wt. \%) hybrid composites", Procedia Engineering 97, pp. 951-960. 
[28] Niranjan, K., and Lakshminarayanan, P.R., 2013, "Optimization of process parameters for in situ casting of A1/TiB2 composites through response surface methodology", Trans. Nonferrous Met. Soc. China 23, pp. 1269-1274.

[29] Zhang, S.-L., Yang, J., Zhang, B.-R., Zhao, Y.-T., Chen, G., Shi, X.-X., and Liang, Z.-P., 2015, "A novel fabrication technology of in situ TiB2/6063Al composites: High energy ball milling and melt in situ reaction”, Journal of Alloys and Compounds 639, pp. 215223.

[30] Habibur Rahmana Md., and Mamun Al Rashedb H.M., 2014, "Characterization of silicon carbide reinforced aluminum matrix composites", Procedia Engineering 90, pp. 103-109.

[31] Mahamani, A., Jayasree, A., Mounika, K., Reddi Prasad, K., and Sakthivelan, N., 2015, "Evaluation of mechanical properties of AA6061- $\mathrm{TiB}_{2} / \mathrm{ZrB}_{2}$ in-situ metal matrix composites fabricated by $\mathrm{K}_{2} \mathrm{TiF}_{6}-\mathrm{KBF}_{4}-\mathrm{K}_{2} \mathrm{ZrF}_{6}$ reaction system", International Journal of Microstructure and Materials Properties Jan 2015, Vol. 10, Issue 3-4, pp. 185-200.

[32] Bosi, C., Garagnani, G.L., Tovo, R., and Vedani, M., 2002, "Effects of matrix and reinforcement properties on low- and high-cycle fatigue behaviour of particulate-reinforced MMCs", International Journal of Materials and Product Technology Jan 2002, Vol. 17, Issue 3-4, pp. 228-24.

[33] Gurusamy, P., and Balasivanandha Prabu, S., 2013, "Effect of the squeeze pressure on the mechanical properties of the squeeze cast $\mathrm{Al} / \mathrm{SiC}_{\mathrm{p}}$ Metal Matrix Composite", International Journal of Microstructure and Materials Properties Jan 2013, Vol. 8, Issue 4-5, pp. 299-312.

[34] Vecchia, G.M., La and D'Errico, F., 2002, "Fracture mechanics behaviour of aluminium matrix composites reinforced with SiC", International Journal of Materials and Product Technology. Jan 2002, Vol. 17, Issue 3-4, pp. 261-274.

[35] Nourouzi, Salman, Esmaeil Damavandi, and Sayed Mahmood Rabiee., 2016, "Microstructural and mechanical properties of Al-A12O3 composites focus on experimental techniques", International Journal of Microstructure and Materials Properties 11.5 (2016): pp. 383398.

[36] Das, T., Munroe, P.R., and Bandyopadhyay, S., 2003, "Some observations on the mechanical properties of particulate-reinforced 6061 aluminium metal matrix composites", International Journal of Materials and Product Technology Jan 2003, Vol. 19, Issue 3-4, pp. 218227.

[37] Vedani, Maurizio, and Elisabetta Gariboldi., 2002, “Creep damage behaviour of Al6061-Al2O3 particulate composites”, International Journal of Materials and Product Technology 17.3-4, pp. 243-260.

[38] Wilson, S., and Alpas, A.T., 1996, "Effect of temperature on the sliding wear performance of Al alloys and A1 matrix composites", Wear, 196, pp. 270-278.

[39] Kok, M., 2005, "Production and mechanical properties of A12O3 particle-reinforced 2024 aluminium alloy composites", Journal of Materials Processing Technology 161, pp. 381-387.

[40] Natarajan, S., Narayanasamy, R., Kumaresh Babu, S.P., Dinesh, G., Anil Kumar, B., and Sivaprasad, K., 2009, "Sliding wear behaviour of Al 6063/TiB2 in situ composites at elevated temperatures", Materials and Design 30, pp. 2521-2531.

[41] Gopalakrishnan, S., and Murugan, N., 2012, "Production and wear characterisation of AA 6061 matrix titanium carbide particulate reinforced composite by enhanced stir casting method", Composites: Part B 43, pp. 302-308.

[42] Suresha, S., and Shenbaga Vinayaga Moorthib, N., 2013, "Process development in stir casting and investigation on microstructures and wear behavior of $\mathrm{TiB}_{2}$ on Al6061 MMC", Procedia Engineering 64, pp. 1183 - 1190.

[43] Radhaa, A., Vijayakumarb, K.R., 2016, "An investigation of mechanical and wear properties of AA6061 reinforced with silicon carbide and graphene nano particles-Particulate composites", Materials Today: Proceedings 3, pp. 2247-2253. 